\title{
Primer
}

\section{Simposio Internacional de Manejo de Pastizales}

A

finales del mes de noviembre del año 2003, se llevó a cabo en la Universidad Autónoma de Aguascalientes el I Simposio Internacional de Pastizales, esto debido a la preocupación de la situación que tenían en ese entonces los pastizales de México y, particularmente, los del estado de Aguascalientes. Tomé la iniciativa de realizar este proyecto académico-científico y fue nuestra máxima casa de estudios la sede del evento. Fungí como presidente del comité organizador. Consideré que en México eran muy escasos los foros relacionados con el tópico relativo a la situación que prevalecía entonces con los pastizales como recurso natural renovable. Debo añadir que resulta innegable el grado de desarrollo de la visión que se tenía de los pastizales a fines del siglo XIX hasta la percepción que hoy se tiene de ellos en 2011.

El evento resultó histórico, a partir de ahí se realizaron seis simposios subsecuentes: Zacatecas, Zac., 2005, Chihuahua, Chih., 2006, San Luis Potosí, S.L.P., 2007, Saltillo, Coah., 2008, y Monterrey, N.L., 2009. En ese año, aprovechando el marco del VI Simposio, el Consejo Ejecutivo de la Sociedad Mexicana de Manejo de Pastizales-SOMMAP, A.C. y sus socios, determinaron que a partir del año 2010, en la sede de Tuxtla Gutiérrez, Chis., se cambiaría de nombre: de Simposio Internacional a Congreso Internacional de Manejo de Pastizales, fue entonces que en esa ciudad se realizó el primer congreso con dicho nombre.

Del 6 al 10 de septiembre de 2011 se efectuó el Segundo Congreso Internacional de Manejo de Pastizales en la ciudad de Chihuahua, Chih. Es preciso señalar que después de 51 años de haberse iniciado formalmente la investigación de pastizales en México y de haber despertado de un largo periodo de letargo, el interés de científicos, técnicos y productores en la conservación de este valioso recurso, se manifiesta en los albores del siglo XXI con más fuerza, a la luz de nuevos enfoques y mayores y mejores herramientas de búsqueda de información a través de medios electrónicos y escritos. Hoy más que nunca contamos con el conocimiento científico, la tecnología y las herramientas necesarias que coadyuvan a la transformación (rehabilitación) o, en su caso, a la conservación saludable del recurso pastizal, asimismo, es conveniente que exista una mayor conciencia de todos los sectores que componen la economía en relación con los múltiples bienes y servicios que aporta a la sociedad, tanto ecológicos como económicos.

Aún con lo anteriormente expuesto, es preciso articular la participación de los distintos grupos sociales y niveles de gobierno en torno a una meta: el aprovechamiento juicioso y permanente del recurso pastizal.

Podemos estar contentos, mas no satisfechos, por lo que se ha logrado en torno a la racionalidad de conservar este importante recurso, aunque falta mucho por recorrer $\mathrm{y}$ hacer en esta materia. 